\title{
RSOC2 10830
}

Queries

John Urry, Robert Dingwall and Ian Gough

\section{Dear Author}

Please address all the numbered queries on this page which are clearly identified on the proof for your convenience.

Thank you for your cooperation

Q1 Latour 1993 - there should not be any references in the Abstract.

Q2 Add correct number for endnote now the notes have been reordered. Should it be note 2 ?

Q3 Sloterdijk, 2005a - add page number of quote.

Q4 de Gulimi et al 2004 - add page numbers.

Q5 Kirman 1995 - add page numbers. 


\section{CHALLENGING ISSUES AND DEBATES}

5

\section{What is 'social' about social science?}

\author{
John Urry ${ }^{\mathrm{a} *}$, Robert Dingwall ${ }^{\mathrm{b}}$ and Ian Gough ${ }^{\mathrm{c}}$
}

${ }^{a}$ Lancaster University, UK; ${ }^{b}$ University of Nottingham, UK and ${ }^{c}$ University of Bath

This is a report on an Academy of Social Sciences debate held on 15 March 2006. The debate concerned the nature, character and development of the social sciences. Four leading social scientists were asked to reflect upon the nature of the social sciences in the light of various transformations in both intellectual thought and in those processes that seem to be restructuring human life as we move into the $21 \mathrm{st}$ century. These changes in different ways seem to problematise the idea of what Bruno Latour refers to as a purified realm of social relations separate from other spheres and around which a social science(s) can be developed (Latour, 1993). Is there a distinct realm of the social and if there is what is it? What is the relationship between such a social realm and other domains? What does this imply for the kind of social science that might be undertaken? These questions were presented to the Academy debaters and all came up with interestingly different responses.

\section{Introduction}

Some intellectual and material currents which problematise the role of human subjects and their apparently unique powers to create and sustain distinctive patterns of a social life include the following. Analyses of 'global' economic/financial, political and social processes reveal their dependence upon an array of global material infrastructures; there are analyses of various 'cyborg cultures' and the implications for humans of increasingly prosthetic technologies; there is the development of a social science of/with material objects as well as the implications of actor-network theory from the sociology of science; there are analyses of the risks of the environment and especially of 'global heating' (Lovelock, 2006) for the future of the human species and hence for social life as it has been known; there are analyses of the partially independent effects of time and space; there are socio-biological attacks on dualistic notions of mind and body and more general awareness of the interpenetration of biological and social processes; there is post-modern critique of meta-narratives of human redemption; there are post-structuralist analyses of the death of the author/

\footnotetext{
*Corresponding author. Department of Sociology, Lancaster University, Lancaster LA14YL, UK.
} Email: j.urry@lancaster.ac.uk 
subject; there are the implications for the human-social world of recent chaos and complexity theories developed from within 'science' and 'economics'; and there is the abiding significance of 'economistic' or 'rational' action explanations of the complexities of human experience.

These four speakers were not expected to deal with all these issues within their 20-minute talk but to draw upon at least one of these streams for their particular 'social' science. In the following we first encounter Paul Ormerod's examination of the struggles within economics to bring 'society' and the 'social' into that discipline, a struggle somewhat refracted through the lens of complexity thinking, path dependence and the limitations of 'economistic' explanations.

\section{What is social about the social sciences? An economist's perspective}

\section{Paul Ormerod}

The most surprising aspect of this discussion for an economist is that it is taking place at all. For economics is slowly but surely becoming more social.

The media gives a misleading picture of what economics is about. Most of the coverage relates to macro-economic factors, such as GDP growth, unemployment, inflation and interest rates. However, economics is fundamentally about individual behaviour, how individual decisions makers (a concept which embraces not only individuals but firms and governments) gather information, and the rules that they use when processing it to arrive at a decision.

For many decades, economic theory was based on the idea of completely autonomous decision makers - people, firms and governments - who each act purely in their own self-interest. Their behaviour is neither directly influenced, nor even mediated, by the behaviour of others. Like so many Robinson Crusoes, agents (the economics jargon word for 'decision makers') operate in isolation, gather all available information and then take the decision that is the best for them, which maximises their utility. Their preferences are fixed and are not affected in any way by what others do.

Their decisions do affect other agents. But the effect is only indirect, via their impact on prices. If I choose to buy a lot more of a given product, it is probable that its price will rise, and so the decisions of others will be affected by the change in price. However, other agents will not, in standard theory, decide to alter their decision on how much of it to buy simply because I have bought it. Their preferences will remain unchanged.

The theory is based upon purely a priori postulates about agent cognition and behavioural rules. Agents are presumed to be able to both gather and process all relevant information. There is a universal rule of behaviour, namely that agents choose to maximise their utility, given their fixed set of preferences. There is no social interaction in this model at all.

The crowning glory of this rational choice theory is the construct of 'general equilibrium'. This establishes the conditions under which a set of prices can be guaranteed 
to exist which ensure that supply and demand balance in all markets. There is no excess supply or demand, and all resources are put to use. It is a formidable intellectual creation, involving the use of some very abstruse mathematics.

By the mid-1970s, the research programme in general equilibrium came to an end. It had finally been worked out completely. All results of interest were known. The conclusion is not particularly good news for the theory. For example, it was demonstrated that the theory contains no testable propositions. So it can never be rejected formally by any empirical evidence. This makes its status as a scientific theory extremely questionable. There is no theoretical presumption that market demand curves slope downwards, so that demand falls if prices rise, and, equally, it cannot be demonstrated theoretically that supply curves slope upwards, with a higher price inducing greater supply.

Of course, many people do reject the theory on empirical grounds, including Kenneth Arrow, who did more than anyone to put general equilibrium onto a modern mathematical basis. Arrow has described the volatility of financial markets as an 'empirical refutation' of general equilibrium theory.

This theory still forms the basis for almost all the economics which is taught. The emptiness of its content is usually only revealed to the very brightest students taking advanced theory courses. Of course, in practice most demand curves do slope down and most supply curves slope up, but these are empirical observations and not proofs derived from rational choice theory.

So 30 years ago, economists interested in expanding the frontiers of the discipline had to move away from the rational choice, general equilibrium framework. There were two entirely separate responses to this challenge, which only now are starting 105 to come together:

(1) Developing theoretical models which relaxed the assumptions made on agent cognition and agent decision-making rules by rational choice theory.

(2) Investigating empirically how agents actually behave, rather than being content with a priori reasoning about how rational agents should behave.

Much of the work in the first category has not really introduced social relationships explicitly. This uses the concept of 'bounded rationality'. Agents are postulated to have only partial rather than complete information, and the amount of information available may vary across agents. There is still a universal rule of decision making, namely that agents maximise, subject to the information which they have. George Akerlof and Joseph Stiglitz were the main pioneers here, being awarded the Nobel Prize for Economics in 2001.

120 All theories are approximations to reality, and bounded rationality extends considerably the areas in which the theory is a reasonable approximation. More importantly, it requires economic theorists to start thinking about the social aspects of their models. The belief in a completely universal model of agent behaviour is abandoned and, as Akerlof pointed out in his Nobel lecture 'in this new style [of 
economics], the economic model is customised to describe the salient features of reality that describe the special problem under consideration'.

In a world in which agents lack complete information, and particularly one in which different agents are able to gather different amounts of information, there is an immediate question as to why this should be the case. An obvious point to consider is the particular institutional framework in which agents in the model operate. What is it about these rules of the game that lead to less than complete information being available, is there anything policy makers can do about it? Admittedly, in many of the papers which incorporate bounded rationality, little attention is paid to points such as these. However, in principle, bounded rationality introduces the idea that agents operate in particular social, institutional settings.

The second, empirical strand of development has led to a more decisive break with the rational choice model. The key names here are Daniel Khaneman and Vernon Smith, Nobel Prize winners in 2002. They took the unusual step, for economics, of investigating how agents really do behave.

There is now a huge literature in the field of 'experimental economics'. In general, most of this evidence suggests that most of the time agents do not behave in accordance with the precepts of rational choice theory. As puts it in his Nobel lecture, 'psychological theories cannot match the elegance and precision of formal normative models of choice, but this is just another way of saying that rational models are psychologically unrealistic' (Khaneman, 2003).

Neither the evidence nor the implications of experimental economics are as yet widely accepted within economics. Criticisms are made, such as the fact that many of the papers in this area describe actual experiments, and the question is raised as to whether these can be generalised into reality. A very fashionable area of economic theory has been game theory, which implicitly places very strong cognitive demands on its actors.

Nevertheless, the main thrust of research in economics has been away from the autonomous agent behaviour in rational choice theory, as evinced by the Nobel prizes conferred upon Akerlof, Stiglitz, Khaneman and Smith.

The current challenge is to construct theoretical models in which individual behaviour is more in line with experimental economics than with rational choice theory. Agents typically have access to limited information, act intuitively and use simple rules of thumb to guide their behaviour.

Progress has been made. An important feature of many of these models is that the agents are placed explicitly in a social context. The decisions of one agent might influence the decisions of another not merely indirectly via the price system, but directly by altering his or her preferences. Preferences are no longer necessarily fixed, but can be influenced by the behaviour of others.

Two early examples are of issues which cause problems for rational choice theory. First, the volatility of asset prices, already referred to above. Alan Kirman (Kirman, 1995) devised a mode in which at any point in time in a financial marker the traders are divided into 'chartists' and 'fundamentalists'. These describe two different modes of behaviour. The former uses extrapolation of recent trends in the price of an 
asset in order to decide whether to buy or sell, and the latter looks at the fundamental features of an asset, such as the profits of a company.

The key feature of the model is that each trader can alter his rules of behaviour in each period, switching from chartist to fundamentalist or vice versa. The main determinant of the switch is the proportion of other traders who were in each category in the previous period. So if, for example, in a stock market boom, as more and more traders believe the market will continue its recent rises, it becomes more difficult for any individual to continue to behave according to the fundamentals, and to believe that shares are over-valued. Of course, at some point this will indeed be the case, but in the meantime it makes sense to behave as the large majority do. Kirman's model comprises a small number of simple (but realistic) rules, which are capable of generating high levels of volatility.

The second example is the question: why do we sometimes see in new technology markets an inferior product wiping out its technologically superior rivals? Of course, to succeed a product must meet certain minimum performance criteria, but above this level there is no guarantee that the best will succeed. In rational choice theory, consumers should learn about the superior qualities of one product and (assuming both are the same price) choose this rather than its rival.

Examples where the best did not necessarily succeed include the QWERTY 180 keyboard, video recorders in the 1980s and the Windows operating system. In each case, there are disputes as to why the eventual winner did succeed, but Brian Arthur (Arthur, 1989) offered a convincing model with simple rules based on=non-linear probability theory. Imagine an urn containing an equal number of white and red balls. One is drawn out at random and put back in, together with another of the same colour. This process is then repeated an enormous number of times.

Arthur proved that the proportion of white or red balls in the urn approaches 100 per cent, but we can never predict in advance which it would be. The analogy in consumer markets is that a new technology with two competing brands emerges. Consumers have no idea in advance of their tastes and preferences. The first person-the first ball drawn out of the urn - buys one of the products at random. This increases, ever so slightly, the probability that the next person will make the same choice. Lacking knowledge about the products, the fact that someone else bought $\mathrm{A}$ and not B may shift your preference to buying A.

In both these models agents use simple rules of thumb to guide behaviour and their preferences can be altered by the behaviour of others.

There are examples of successful models-successful in the sense that they give a good explanation of complex empirical phenomena - in which agents act as if they had zero cognition. Here, it is the institutional setting that accounts for the success of the models.

Farmer et al. (2003) are able to replicate many subtle properties of asset price 200 changes in a model in which traders have by assumption zero intelligence. They buy and sell at random. It turns out, for reasons which are not yet understood, that the properties of price changes arise from the price setting mechanism. This, the continuous double auction, is a feature of many real-world markets. So the institutional framework is essential. 
Ormerod \& Rosewell (2003) account for subtle properties of firm extinction patterns (e.g. de Gulimi et al., 2004) with a model in which firms act as if they had zero cognition of either the consequences of their actions on the fitness for survival of other firms, or of the impact of the actions of others on their own fitness. The key feature here is that firms are connected to each other with as set of direct pair-wise connections, and the (random) actions of one firm can percolate in unexpected ways across the entire system.

Increasingly, economists are constructing theoretical models in which agents act in a social setting. The particular institutional framework might be decisive for the outcome, agents might alter their preferences on the basis of the decision of others. The rational choice, purely autonomous agent still holds sway in research and even more so in teaching. But the direction of change is to incorporate social settings into economics.

\section{Introduction}

Some of the ways in which space and spatiality are to be seen as enfolded into the notion of the social and of the social settings Ormerod refers to are examined by Doreen Massey who emphasises the multiplicities and political implications of such contrasting 'spaces'.

\section{What is 'social' about social sciences? Some reflections on the mutual necessity of the social and the spatial}

Doreen Massey

I want to begin from the proposition that the social (standing on its own as a term and not necessarily attached as an adjective qualifying 'sciences') is fundamentally concerned with the more-than-one. That is to say, it is a reference to the fact of multiplicity, the implacable fact of plurality. It is concerned with the essential interrelatedness (and in that also including the possibility of the lack of relatedness) of existence. It is concerned with the fact, not just of 'being', but of 'being-with'. An exploration of the social is therefore an exploration of the nature and the possibilities, and the challenges, of that 'with'.

In the invitation to address this question ('what is social about social sciences?') I was asked particularly to focus on 'space'. In fact, I should like to argue, the social and the spatial presuppose each other. They are twins. It may be indeed that it is that very essential mutual necessity that has led to the spatiality of the social being so frequently neglected. It is almost too obvious to be noticed. Yet the realm of the being-with, the dimension of contemporaneous multiplicity, is necessarily the realm of the spatial. Space as a dimension presupposes, and is presupposed by, multiplicity in the simple sense of the contemporaneous co-existence of more-than-one. The social presupposes the spatial, by definition therefore, and vice versa. Without 
space (as a dimension) there could not $b e$ the multiplicity that is intrinsic to the social, and without multiplicity there would not be space. ${ }^{1}$

Space, then, is the dimension of possibility for the configuration of the multiplicity that is the social. ${ }^{2}$ It is a dimension that emerges (it is produced) through the practice of relating (and not relating). In consequence, it is an ongoing creation, always under construction. It is never a completed whole but always open to a future that itself is open. It is therefore in some manner, and as is the social, a responsibility. As social beings, including as social scientists, it is a dimension to which we must attend.

The briefing paper that accompanied the invitation also made reference to timespace, and the hyphenation and the nature and implication of the hyphenation is significant. On the one hand, as is so frequently argued, it is important not to counterpose space and time; they must be thought together. Indeed, each is integral to the possibility of, and the production of, the other (see Massey, 2005). On the other hand, they are nonetheless distinct. If time is the dimension of change, space is the dimension of the social, the contemporaneous coexistence of others. At one point Jacques Derrida made a distinction between space as the dimension that requires of us that we respect, and time as the dimension that requires that we take upon ourselves responsibility. This may be a distinction that is too sharp but what it points to is space as the dimension that presents us with the existence of the other. Prior

260 to any action being taken (in time) to respond to that existence, an attitude must be struck; a stance must be adopted in relation to the simple fact of that existence. (The 'prior' here-and this is the point at which one might have mild reservations about the Derridean formulation-is conceptual rather than chronological.) The other(s) may be in our eyes misguided, or simply wrong, or may even be 'the enemy', but regardless of (prior to) the particular nature of our response what a full recognition of the spatiality of that co-existence requires is simply the acknowledgment of co-evalness (Fabian, 1983). Space in that sense lays the groundwork for that most fundamental of social, political, ethical, questions: how we are going to live together. That is, perhaps, the motivating question behind all our enquiries as social scientists. That is the 'social' in social sciences.

Therefore, a political cosmology that takes seriously the mutual integument of social and spatial presents a serious challenge. It places demands on the procedures of the social sciences and it (potentially) places on the social-science agenda the need to engage in critique of political cosmologies in society more widely. For it is in part through these spatio-temporal orderings that the world is understood, that social and political questions are framed, that hegemonic imaginations are established and maintained and particular courses of action are thereby legitimised.

Indeed, the challenge of space is such that we often adopt evasive geographical imaginaries to deflect it. This happens both in society in general and within the social sciences themselves. I consider here two brief examples, explored more fully elsewhere (Massey, 2005).

First, space is often figured as a surface. It is, for instance, frequently equated with maps or with the landscape. People are said to travel across space as though it were a flat plain. Perhaps this is a version of the notion of space as extension rather than as 
multiplicity (see endnote ?). So 'voyagers of discovery' set out across space and come upon 'others' (Aztecs, Incas, those of the heretofore 'undiscovered' world) just there, on this spatial surface. In this time-space political cosmology, there is only one active agent (here, the discoverer). It is a classic colonial imaginary. The already ongoing histories of those 'others' are suppressed. This is the implicit conceptualisation of space that underlies what Wolf has famously called 'the people without history' (Wolf, 1982). What is suppressed here is precisely multiplicity, the multiplicity of the spatial that is essential to the social. Nor is this an imaginary confined in its deployment to the analysis of historical phenomena. The conceptualisation of globalisation has frequently been as an outward flow across a planetary surface towards effectively passive recipients. Within the social sciences it is this implicit conceptualisation of space that underpins some unsophisticated versions of trickle-down economics.

Or again, there is that evasive imagination that turns space into time, geography into history. In those discourses of globalisation, or of development, in which countries or regions are imaginatively rearranged into historical sequence, this is what is going on. Sequences of necessary temporal orderings, for instance: developed, developing; advanced/backward; and some of the most presumptuous of stories of modernisation and progress. In all of these there is a conceptual manoeuvre by which contemporaneous difference (the multiplicity of the spatial) is imaginatively reconstructed as temporal sequence. Not only is the challenge of the spatial thereby occluded, but the temporal itself is rendered as singular. There is only one history, one temporal sequence that all must follow. Once again, multiplicity - the essential condition of both space and the social - is suppressed.

It is important to be clear here. This is not an argument against any notion of 'progress' tout court. What is under examination is rather the singularity of the notion and the question of who it is that gets to define that hegemonic concept. One obvious benefit to those deploying temporalised concepts such as developed and developing, for instance, is that this formulation, through its very temporal alignment, occludes the possibility that the inequality that these terms are in fact referring to is in part produced by actions, practices and power-relations in the here and now. It evades the question of the simultaneous co-existence of these states and of interaction between them. It evades the responsibilities of multiplicity.

Turning space into time is the implicit geographical imaginary underlying the assertion that there is no alternative. There is only one history, and only one possible future. This is the discursive manoeuvre constantly deployed by Tony Blair and New Labour in their insistent appeals to 'modernisation': there is only one way forward and those who resist it are automatically characterised as resisting any form of change at all. They are, precisely, consigned to the past (they are old fashioned, Old Labour, or whatever). It is a manoeuvre that precisely avoids engagement with the possibility that there may be alternative ways to go forward, alternative futures it might be possible to build.

It is all too easy to have recourse to such imaginaries. On the occasion of the re-election of George W. Bush much of the progressive left gave vent to a despair that frequently resonated with such feelings. How could so many people be so 
committed to a litany of family values, homophobia, anti-abortion, religious fundamentalism? How could they possibly think like that in the 21 st century? The exasperated question is, to say the least, understandable. Yet it is, I would argue, at least insufficient if not downright wrong. For one thing, it avoids the respect intrinsic to the recognition of co-evalness. This is the 'respect' that is prior to the engagement (in this case contestatory) with these positions. Indeed, the relegation of people to the past also disables such engagement, by evading analysis of what has produced such political opinions now.

It is has been argued for some decades now that 'we are entering the age of the spatial'. In Bruno Latour's political proposal for $A$ (philosophical) platform for a left (European) party, the third of his 10 planks begins 'I have the feeling that we are slowly shifting from an obsession with time to an obsession with space' (Latour, 1999, p. 14). A little further on he reflects that:

If, as philosophers argue, time is defined as the 'series of succession' and space as the 'series of simultaneity', or what coexists together at one instant, we might be leaving the time of time-successions and revolutions-and entering a very different time/ space, that of coexistence. (p. 15)

I have some reservations about this formulation. It itself, somewhat contradictorily, has the flavour of linear temporality and singular movement (who is this 'we'?!); its account of the emergence of the spatial ironically relies on the temporal (Grossberg, 1996); and I am not sure whether, in fact, such a shift is occurring. Certainly, too, I would not want to argue for an obsession with space, nor for the replacement of time by space; nor indeed am I so simply dismissive of all previous politics of the revolutionary left.

Yet Latour is catching at something important: what taking space seriously does require is an engagement with the co-existence of multiplicity. It means moving away from a framing imagination of a singular linear progression towards an imagination expansive enough to take on board also the configurations (actual and potential) of co-existence. In that sense it means taking on board seriously the fact of the multiplicity that is the social. So the briefing paper posed the question if there is anything left to the specifically social, separate from time-space. One part of a response, in terms of an understanding of the social proposed here, might be that time-space configurations are crucial to what is at stake in the constitution, the analysis, and the challenge to, the social.

355 Finally, the paper asked us to reflect upon what it called 'socio-technical changes'. Certainly, over the last half century there have been radical shifts in the spatial structuring of the social. We have been making space in vastly different ways. This in turn has raised (or heightened the significance of) a number of issues for the social sciences. Some of these are almost terminally mundane yet they do perhaps bear 360 listing, if only briefly. Among the most obvious are the following. First, that space in the social sciences, and 'spatialising' the social sciences, should refer to more than the fact of geographical differentiation, and specifically to more than territorialised differentiation (where a study is 'spatial' because it compares Stockport and West Bromwich). There are two distinct aspects to this. On the one hand, 'the 
spatial' should refer to the whole intricacy of the configuration of trajectories. On the other hand, geographical variation in such configurations can not be assumed to be territorial. Second, rather than assuming the existence of, or even the need for, placebased community (intra-area coherence), there should be attention to the way in which place is negotiated across difference (place as a meeting-up of potentially disparate trajectories). There should be more attention too to the wider, sometimes global, geographies of the everyday that are implicated in that. Third, and it is disappointing that this point still needs repeating, there should be a stricter recognition that the causes of any area's characteristics do not lie solely within the area itself. It is no part of a serious spatialisation of the social sciences to reify the spatial. Yet this tendency is widespread, perhaps most particularly within policy work. Fed perhaps by a (necessary) mapping of social characteristics (employment, levels of health, GDP per capita) a veritable moral geography is erected, in which some regions/places/ countries fail while others succeed. The London region 'succeeds' (whereas in fact it is both source and beneficiary of the turn to neoliberalism). Council estates are pathologised. This attempt to explain spatial differentiation within the areas themselves fails to recognise that all geographical 'entities' are embedded in and constituted through proliferating wider and more systematic geographies. The effect is to let these wider causes 'off the hook'.

However, if the above points are now somewhat ritual (even if, for all that, largely disregarded), there are two others that are of greater urgency in the current conjuncture. They are linked (these are further spelled out in Massey, 2004). The first is that we need to think more clearly about the wider geographies of obligation, care and responsibility. These are now, in a thoroughly interdependent world, thoroughly global. On the one hand, while the formalities and particularly the electoral bases of so much of our politics is territorial, the relations that underpin our lives and the effects of our lives are by no means so. The geography of political claims and responsibilities is deterritorialised (which does not mean that the territory - the nation or the local place - may not be a good base from which to organise a response to those claims). On the other hand, engaging with this new (or newly evident) spatiality should mean extricating ourselves from any notion that the originating, iconic, form of care, responsibility, and so forth should always be seen as being local—in the home, or the family.

Second, and following on more generally from this, I believe we need to be more global in our attention. I do not mean this (only) in the sense of, say, studying globalisation, but rather in the sense of a greater and richer framing awareness of the amazing complexity and variety of the planet as a whole. Anthony King suggests, for instance, that we write about cities (and usually first-world ones at that) because that is where we live (I do not exempt myself from this criticism!). We have become obsessed with the question of the relational construction of identity, but our concern has been mainly to look within, at the fragmentation, the internal multiplicity, the decentralisation. Yet what of the relations, of this relational construction of identity (of an individual, a group or a place), that run outward around the world? We are concerned, quite rightly, with hybridity within, we repeat and repeat that cultural 
diversity can now be found at home (and it can). But that does not mean that there is no need to look elsewhere. Perhaps we need to be more outward looking.

Finally, and to return yet again to the briefing note: it referred to texts and technologies, to non-human and trans-human things. The proposition that the social is about being-with, arising essentially from the fact of multiplicity, is not restricted to the human. One need only think of Latour's networks, to recognise that. However, the implication of this is that the question posed by the existence of multiplicity (the conjoint existence of the social and spatial) 'how are we going to live together?' in turn poses a further question (which I am not going to answer here) which is: who is this 'we'? Is it just human beings?

\section{Introduction}

John Scott seeks to hold on to a distinct realm of the social that is concerned with the intersubjective relations between people, and that this is and should be the province of sociology as a distinct bounded discipline.

\section{Sociology and the social: a qualified defence of sociological imperialism}

\section{fohn Scott}

I would like to approach the idea of the 'social' by exploring questions of disciplinarity and interdisciplinarity, beginning with an attempt to set out what might be specific to sociology as a social science. Some of these arguments are developed in Scott (2005a, 2005b). The distinctive object of study for sociology is the social, understood as the sphere of intersubjective, culturally formed relations of interaction and interdependence. This distinctively social aspect of human existence was the focus of the disciplinary reflections of the formative sociologists, and was most notably explored, in varying ways, by Durkheim and Simmel. For these writers, 'society' emerges in and through symbolically constituted encounters and interactions, organised through linguistically mediated communication, and through the meanings and representations that pass from one mind to another in the course of intersubjective association.

However, the social is not to be seen as an ethereally static realm with no substantive existence beyond individual minds. There is, of course, no 'group mind'. There are, rather, collective fields of shared meanings that constantly circulate among minds and exhibit sui generis properties that cannot be explained solely in individualistic terms. These fields of meaning change over time and have a substantive existence in and through material objects.

440 Temporal change is a crucial property of the social. In so far as it is produced and reproduced in interaction, it is also subject to constant transformation as individuals innovate and improvise, perhaps while misinterpreting each other's meanings. Therefore, social phenomena are in a state of constant flux. Questions of temporality are inescapable. 


\section{F. Urry et al.}

Social phenomena must also be seen in relation to their materiality, both the materiality of the human body that is the vehicle of interaction and the larger material world that constitutes the environment within which those bodies move. Social relations are embedded in material objects as a spatial 'morphology', and while the social cannot be reduced to its morphology, materiality is necessary feature of social phenomena.

The distinctive and defining feature of the social, then, is its intersubjectivity, but this must be seen as a temporally organised and materially embodied intersubjectivity. This highlights the complex relationships between sociology, history and geography, as the three foci of social science. Indeed, sociology could, in some respects, be held to be indistinguishable from these other disciplines, which are differentiated by their particular and distinctive focus on, respectively, the intersubjective, the temporal and the spatial.

In practice, of course, there have been important, yet contingent disciplinary differentiations. History has tended to define itself by a concern for chronological narrative and to be an 'individualising' or 'particularising' discipline rather than a generalising one. History as it has developed as a university discipline has also tended to draw on psychology and other disciplines in its explanations, rather than seeing itself as exclusively 'social' in character. Its recent self-definition in the 'benchmarking' activities of the UK's Quality Assurance Agency concerned with teaching quality within all fields of study, saw history as a discipline defined by its concern for 'the past'. Geography has tended to define itself more analytically by a concern for the specificity of place and the materiality of space, a distinction that is most easily sustained through its continuing (if sometimes uneasy) association with geology, geomorphology and climatology in a discipline divided into 'physical geography' and 'human geography'.

However, much substantive geography, like much history, is indistinguishable from the work undertaken by many sociologists. We cannot make sharp and ultimate distinctions between these disciplines. Their contingent and arbitrary character as products of specific processes of educational development in modern societies must be recognised as the major determinant of their particular concerns. Perhaps the key mark of a distinctively sociological approach to the social, however, is its concern for generalising reflections, that is, for the development of theories of the social. While history is concerned with temporality and geography with spatiality, sociology is concerned with theorising the nature of temporally and materially organised social activities. Social theory, then, has been, and must continue to be, the distinctive focus of sociological work.

This leads me to conclude that sociology is, in many senses, the core discipline of the social sciences. In theorising the social it is concerned with what is specific to all of the social sciences and that divides them off from the natural sciences and the humanities. This might lead some to accuse me of espousing Comte's view of sociology as the Queen of the Sciences and, perhaps, of being an advocate of sociological imperialism. With some reservations I plead guilty. Sociology can legitimately concern itself with anything social. Thus, economics, urban studies, political science, religious studies and so on, might all be considered - again with reservations - as 'branches' 
of sociology. Such claims might not be welcomed by those within these various disciplines, but in so far as they are social sciences the claim is, I believe, incontestable.

These highly specialised forms of social science should not, of course, be organisationally assimilated to sociology. My position is, rather, one that stresses the importance of interdisciplinary cooperation among the social sciences. The claim that sociology is central to their character as social science has two implications.

First, the generalising theories produced within these sciences are specialised forms of social theory, and work in any one discipline cannot ignore more general forms of social theory, any more than the general theories of sociologists can afford to neglect the arguments of economists, political scientists and others. A social theory that ignored the economic, for example, would be seriously inadequate, and Paul Ormerod has shown the problems inherent in an economic theory that becomes too detached from wider arguments in social theory.

The second implication is that the substantive empirical work engaged in by sociologists and others can rarely be contained within existing disciplinary boundaries. Any adequate investigation of a social phenomenon is likely to involve those who study it in interdisciplinary work or, at the very least, in work that has implications for those in neighbouring disciplines and specialisms. Indeed, it is for this reason that many new 'interdisciplinary' areas of study arise: specialists within established disciplines begin work on a particular topic that draws them together and, on occasion, new disciplines are born precisely from this interdisciplinary overlap and collaboration.

The crucial role of sociology is to hold the central position within these debates and disciplinary fissions. Economic, political and other forms of action are always embedded in a larger social context, to a greater or lesser extent, and so they cannot be sharply distinguished from sociological concerns. The differentiation of concerns amongst specialised disciplines can never, therefore, be total and complete.

There are similar implications for the specialisms that emerge within sociology itself. As human social life has become more complex and differentiated so new areas of sociological enquiry have emerged. Alongside, and often replacing, established specialisms have emerged new sociologies of consumption, leisure, the body, the mass media, travel, and so on. In many of these specialisms, cooperation with those working in established disciplines and interdisciplinary areas is unavoidable. Sociologists working on travel and transport, for example, work closely with geographers and others in developing their arguments. Such specialisms often split off from the parent discipline to become new disciplines in their own right. Whether they become established as new 'disciplines' with their own organisational structure within the university system or remain as looser areas of 'interdisciplinary studies' is often arbitrary, and relatively unimportant for the character of the work undertaken.

One consequence of this process of disciplinary and interdisciplinary formation is that sociology tends to 'lose' areas of study to the new subject areas. Specialisms within sociology become disciplines apart from it, and there may be a mass migration of researchers from sociology to the new discipline. Traditional industrial sociology, for example, virtually disappeared with the expansion of business studies in new 


\section{F. Urry et al.}

Departments/Schools of Management. Some have drawn the conclusion that sociology is simply a residual discipline-sociology has the 'left-overs' after other specialised disciplines have taken their bite at the social. A logical corollary drawn by many who take this position is that the social sciences could exist perfectly happily without sociology. If more and more areas split off from sociology, then sociology will be left with nothing to study, yet everything social will be studied somewhere else in one of the specialised social sciences.

There are two problems with this argument. The first is that it does not recognise the constantly changing nature of the social and, therefore, the constant emergence of new social phenomena that must be studied. Such phenomena are marginalised or ignored by specialised disciplines concerned with their particular set of issues. But because there can be a sociology of anything, such new phenomena find their natural home within sociology. Sociology, on this view, is constantly rejuvenated. Although it may lose specialist areas to new social sciences, new areas of investigation grow up to take their place. Indeed, sociological investigations of economic life have experienced exactly this. While many traditional concerns of industrial sociology have disappeared from within the discipline of sociology, new concerns for consumption, retailing, and new forms of work have expanded to form lively specialisms within sociology.

The second problem with the argument from left-overs, takes us back to my earlier argument about social theory. If sociology were to disappear, there would be no discipline that took the social per se as its distinctive concern. While specialist bodies of social theory might be developed within specialised social sciences, there would be no general social theory and, in the long-term, the specialised social theories would be diminished and the disciplines would be weakened. This is, perhaps, the real danger in the arguments of those who decry old-fashioned disciplinary concerns in the name of interdisciplinary work. New interdisciplinary work must be encouraged, and interdisciplinary cooperation must also be encouraged, but this should not be at the expanse of those disciplinary divisions that are crucial to the survival of the social sciences themselves. The development of the social sciences since the late 19th century has depended upon the development of sociology, and it is difficult to envisage the social sciences continuing to thrive without the continuing development of sociology.

I return, then, to my starting point. The social sciences require the existence of a strong disciplinary sociology, but a sociology that is open to its relations with other disciplines. It is the commitment of sociology to the development of a general social theory that is crucial. Such a theory that encompasses not simply those things studied by 'sociologists' but also the concerns of other social scientists. It is for this reason that it is more plausible to describe it as 'social theory', rather than simply as 'sociological theory'. Sociology is the science of the social, and its theories concern the social world as a whole and not merely those things that happen to interest empirical sociologists at the present moment. A social theory is necessarily outward looking: it is aware of the temporality and materiality of the social, and it recognises the multidimensional character of the social itself. 
Therefore, advocacy of a strong disciplinary sociology is not an advocacy of intellectual purism or a conservative and defensive reaction to new interdisciplinary areas. My advocacy of disciplinary sociology concerned with the development of general social theory should be seen as designed precisely in order to encourage fruitful cooperation with other disciplines and to welcome the restructuring of existing sociological concerns as established specialisms split off and new specialisms emerge. A strong disciplinary sociology is the only basis on which vibrant interdisciplinary collaboration can be envisioned and furthered.

A focus on the idea of the social allows us to recognise and welcome the shifting intellectual contours of the social sciences and underlines the central role of sociology within that intellectual landscape. A concern for a general theory of the social-for the study of 'society' in all its complexity - is the core of the sociological imagination, and the sociological imagination must be fostered in all social sciences.

\section{Introduction}

Nigel Thrift examines a wide range of intellectual trends that undermine a clear sense of the social but concludes that there are some distinct new ways of newly thinking about the intersubjective social bonds discussed by Scott.

\section{Dropping the pilot?}

\section{Nigel Thrift}

I am certainly not in favour of just jettisoning the social, even if it were possible to do that with a notion that now has such wide currency, and not least because of the political resonances of making such a move. But, at the same time, it would be difficult to deny that the term has fallen on hard times. It looks a bit frayed at the edges, a bit run down. To me, the reasons are threefold. First, a series of approaches from within the social sciences, such as those emanating from a good part of the sociology of science, have seemed to want to disavow the word (although without, it has to be said, much indication of what exactly might replace it). Second, a series of approaches from without the social sciences have likewise poured scorn on the notion, from approaches that downgrade the notion of science itself (often, ironically, using extreme versions of social constructivism) through to approaches such as deconstruction which continuously remove the term. Then, finally, there is an obvious politics to all this, all the way from those who do not believe in something called 'society' to those who believe that it is in some way an ethnocentric term, and those who just believe that the term leaves no room for other entities to flourish.

600 There are sound intellectual reasons for a certain degree of scepticism, I am sure. These, I think, involve the ability of any term to fit all that is going on in the world. Most than most, or so it seems to me, the particular frame 'the social' represents has overflowed. It can never again be the term around which others have to fit, or a generalised prefix. At least four different but linked kinds of overflowings have 
occurred, each of which represents a certain kind of going-on that the social has conventionally found difficult to recognise (although, like all generalisations, there are particular authors who prove to be exceptions to this rule). None of these overflowings need or want to be invited back in to the social. Rather, they are demanding parity, or a new game entirely.

The first overflowing seems to me to be around things. Things often used to be thought of as dumb, animated by social and cultural representations. That seems to me to be an impossible stance to maintain at present. Things have a presence that is so pervasive that it can no longer be domesticated. From the formative social impacts of objects like barbed wire (brilliantly captured in Reviel Netz's recent Barbed Wire, 2004) through the by-now vast literature on consumption to the growing work on a phenomenology of indifference, things increasingly seem to be thought of as a kind of ante-consciousness, a spreading so extensive that they can come to the surface in all sorts of lives and leavings simultaneously. I believe that this has a lot to do with the advent of totally managed environments since the end of the 19th century, environments which have become ever more pervasive, ever more modulated as a result of a whole series of technologies working in synch (well, at least, an approximation of it). This 'technological unconscious' seems to have spread, becoming a carpet of expectations about how the world will turn up (Thrift, 2005a).

The second overflowing is provided by nature. I would want to talk instead about biology for it is clear that biology is a fundamental force which cannot be fenced off as if it occupied some separate sphere. Directly at least, biology has begun to impinge in to the social sciences in all kinds of ways and by no means all of them are about reductionist approaches which simply read the social as an expression of some equally centred biological domain (Thrift, 2005b, 2006). These mainly associative currents of work subscribe to the view that the biological is not something different in kind from the social but is an integral part of the business of building collectives. But they also index the rise of 'biosocieties' which include all manner of issues including: the manipulation of heritability and explicit biological engineering of various kinds (e.g. bionanotechnology); the direct manipulation of body parts via procedures such as transplantation, and now xenotransplantation; the number of public currents of concern that refer to biological issues, from the treatment of farm or laboratory animals through to concerns about genetically modified organisms through to all the different means of cohabitation that have now become apparent, and; the consequent proliferation of social imaginaries that now refer to the biological as constitutive.

The third overflowing is provided by the psyche. It seems impossible, to me at least, to argue that the unconscious has no purchase and can simply be read off as a social construction. Although I am no particular fan of endless psychoanalytic interventions, it seems to me that the unconscious is making a comeback in various new guises, as the realm of so-called bare life, as a new round of work on imitation-suggestion and mimesis more generally (as in the work of Girard, for example), as an enquiry into automatisms of various kinds (most notably motivated by feminist interventions of 
various kinds), as a reworking of our understanding of the power of crowds, as a crucial element of globalisation, and as the seemingly endless conveyor belt of works by Slavoj Zizek (who seems to be outproducing capitalism at this point in time).

Fourth, there is the overflowing provided by extreme experience. It seems to me that experiences like pain, suffering, violence and trauma can be seen as direct challenges to a bounded notion of the social. Although often conceived as disclosing some basic truth about the definitive character of society, they can equally be seen as part of a struggle to establish whether there is an adequate conception of the senses of violation and redress at the level of social meaning (it is all too much) (Wilkinson, 2005). They also seem to include within them moments such as those in which bodily meaning exceeds all social interpretation, confounding its logic and scrambling its expectations (as in Deleuze's discussion of the scream). But they can also be seen as salutary sensory indexes of the true range of being human, now being drawn in to the realm of production as part of a general intellect or some similar expression of the power of expression.

None of this is to suggest that the greats of the social science canon never considered any of these matters (think only of Weber on affective action, anchored in the emotional state of the actor rather than in the rational weighing of ends and means, or Durkheim on suicidographic currents, for example). But it is to suggest 660 that, to a degree at least, we are moving on and that current 'cultural' attempts to recuperate the social (such as Jeffrey Alexander on performance) (Alexander, 2006) are unlikely to entirely succeed.

That is not to say, of course, that our thinking has been paralysed by these overflowings. Quite the reverse, in fact. If anything, I think it is possible to argue that they are 665 stimulating a great wave of work across the social sciences, work which is attempting not so much to jettison the social as to rework it. To illustrate my point, I thought I would conclude by pointing to just three theorists who have attempted, or are currently attempting, to work through these dilemmas. I will go back in order to come forward by starting with the work of Gabriel Tarde. Then I will move to the recent work of Paolo Virno and Maurizio Lazzarato, and finally Peter Sloterdijk.

Why has Tarde's work been resurrected of late? There are a number of reasons of course, but one of the most obvious is that he refused to make a divide between the social and nature. Insofar as he was willing to countenance the use of a term like 'the social' at all, it was to refer to the complete range of entities that exist in association. As Lazzarato (2005) puts it:

Tarde's sociology is not a science of the social according to the categories of sociology. It is an understanding of 'associations', of co-operation, with no distinction made between Nature and Society. It is the sociology of atoms, of cells, and of man. Tarde takes Durkheim's premise that the social is a fact and must be analysed as such and turns it on its head. 'All phenomena are social phenomena, all things a society'. (p.17)

In turn, Tarde provided a series of models of that which flows out from (or perhaps more accurately, through) us unawares, models of imitation and invention. These models serve the present hyper-mediated moment well, emphasising as they do nonconscious perception, dissociation, suggestion and suggestibility, and social influence 
as forming a part of a stream of thought, rather than a threat to the boundaries of an individual. Although Tarde was of his time, he was also an original in his emphasis on understanding imitation as a process of snowballing mimetic desire, as reverberating circles of influence, rather than as simple mechanical copying, and on his insistence that imitation formed a basic process of social life that was governed by laws of regularity which could be attributed to the action of invention. Invention itself was also considered as a social process by Tarde, one which determined which ideas spread, and which did not.

Tarde's work is used as a resource in the recent writings of Paolo Virno and Maurizio Lazzarato, both of whom track the move from 'capital-labour' to 'capital-life' in which capital takes on all the powers of the transindividual general intellect-'knowledge, the subjective spirit of invention, invention-power'-by tapping in to the full range of psychophysical powers of the human body rather than just labour (Lazzarato, 2005 , p. 21) 'In a way, labour is today truly productive (of surplus value and profit) only if it coincides with the human abilities that previously explicated themselves in non-labour' (Virno, 2006, p. 38). So 'labour power has become invention-power' (p. 37). In other words, the whole of human praxis, all of the generically human gifts, come to be included in the productive process. 'Contemporary capitalist production mobilises to its advantage all the attitudes characterising our species, putting to work life as such' (Virno, 2005, p. 35, author's emphasis). This expanded praxis can both produce, hasten and adapt to the vagaries of the nonlinear productive fluctuation that typifies modern capitalism (Thrift, 2006).

In contrast, Sloterdijk takes Heidegger on dwelling as a point of reference but then spatialises his thinking by posing the question of being as the question of beingtogether: 'one is never alone only with oneself, but also with other people, with things and circumstances; thus beyond oneself and in an environment' (Sloterdijk, 2005a). 'Being-a-pair' or a couple precedes all encounters. In other words, being in the world is concerned with the dynamic of spaces of co-existence, spaces which are commonly overlooked, for the simple reason that 'human existence ... is anchored in an insurmountable spatiality' (Sloterdijk, 2005a, p. 229). On the basis of this analysis, Sloterdijk suggests that what the current moment requires is an 'air-conditioning project' that can sweep through the totally managed and domesticated spatial environments of current existence. This project of the ventilation of the atmospheres of modern life will provide new environments in which novel doctrines of living can thrive, environments which will provide the breathing space with which democracy can be re-invented, just as the original Athenian democracy was critically dependent upon the city and 'the pre-logical or pre-discursive premises of the art of urban co-existence' that were able to be constructed from it, premises that were the result of 'the skilful application of anti-misanthropic procedures' (Sloterdijk, 2005b, p. 947).

All this said, there seems little doubt to me that each of these three approaches ends up wanting to strengthen something that looks very like a social bond. Tarde seemed to be aiming for an almost perfect affective bond of love: there would be 'no other country than the woman or man you love', Virno and Lazzarato are aiming for a 
society which uses the presence of others as a transindividual resource and which somehow thereby enlarges sympathy, Sloterdijk wants to invent new political environments in which novel doctrines of togetherness can thrive. So, or so it seems to me, it might be better to say that the social has now expanded to include a much greater range of active characters, many of them with different powers from those conventionally regarded as human but each of them with something to say. The best analogy I could think of is with those multi-player games that are populated by all kinds of magical beings which have particular powers that can only be brought into play in particular ways and in particular situations. However, more to the point, it is also about designing institutions that can give all these actors some degree of representation, not as an act of charity but as a means of expanding what it is to be human. After all, Leo Tolstoy's famous question still remains: 'what shall we do, and how shall we arrange our lives?' and, to me at least, that still implies a society, no matter who the we is.

\section{Debate}

Question: I wonder if I could ask a question relating to two of the speakers; the way that Thrift ended by posing the issue of the social expands to include a much greater array of agents and actors and he implied this would raise some problems with what Scott was saying. I wonder if we could ask, with the two of them here, what on earth would it be like to construct a social science in which there were this exceptional diversity of agents who are interacting, some of which are social, with certain of the characteristics that are being identified and some are other kinds of things; objects, text, infrastructures and so on.

745 Thrift: Well in a way I suppose you could argue that is precisely what many people are actually trying to do at the moment. Now they do not know what it looks like. It is a series of experiments, but for example, it seems to me that areas of sociology of science, is precisely trying to do that and certainly Actor Network Theory claims to be doing it as well. We could argue backwards and forwards about how successful we think they are but it is certainly the case that such visions do exist.

Scott: I tend to see it as a rather forced contrast in some ways, I tried to make a distinction between what I called the narrow conception of the social and the broader conception, precisely to recognise the interdependence of these. The importance of highlighting the narrow conception of the social in the sense of intersubjective encounters was to imply that the social cannot be reduced to thingsnature, psyche, etc.- there is something else left over that we have to take account of and in many ways that is the core of what it means to be social. Although that has to be the distinctive concern of a social science it is not the exclusive concern. The social, even understood in the narrow sense, always exists in par760 ticular material context-and I do not think any of the important social theorists have every denied that. What I think of is Durkheim's arguments on social morphology: that social facts exist only in their materialisation in particular physical arrangements, and so on. There is also the whole question of the role of things in the form of technology, as understood in the idea of the means of production 
in Marx, and so on. So I do not think that these things have ever been ignored, I think that what may be important is that perhaps one of the assumptions in a lot of social science in the first half of the 20th century was that the development of human technology was making it possible to master and control nature in certain ways and that therefore human life was becoming, at least partially, autonomous and detached from nature. As we know, in the second half of the 20th century nature has bitten back and we have come to realise the limits of technology. So, I think it is not so much that one had, before, a conception of the social that ignored technology, things, and nature, but that they were seen in specific ways and the world in which we live has changed because of the social changes that have transformed the natural environment in which we live.

Question: I have been to these debates elsewhere, where people have argued very strongly that individuals come together entirely under their own self-interest and that a couple, or a partnership, is actually just two self-interested individuals that come together and are operating under a model of rational action. Now Scott says that there should be bedrock of social theory which might dissipate if the whole thing is spread too wide. You could argue that those that are going towards rational action theory could be seen as the enemy within social theory. And yet you have all been very friendly about the need for the social, so we have not heard a really trenchant criticism of the social. It was only Thrift that said that the social is going through a 'bad patch'. But the real reasons for that have not come out, and therefore I wonder if anyone wants to play devil's advocate (and adopt rational action theory). Scott: There is a sense, obviously, in which many of the rational action theorists are more imperialistic than even I was implying. This is inherent in the notion that rational action theory can be applied to anything and everything. But Paul Ormerod demonstrated the limitations of that kind of argument. Perhaps the reason why rational action theory has moved into other areas of social science from economics is because of the exhaustion of the intellectual problems within economics itself.

790 Ormerod: Yes, rational choice theory is exhausted within economics, but other social science disciplines might seem easy prey for those wanting to use it. It is not completely without insight. There is a very powerful discovery which economics has made. Namely, that agents react to incentives. It is so well established that it is the only general rule of behaviour we have in social sciences. This certainly does not mean that decision makers necessarily react to incentives in the way that rational choice theory says they do. But just this one rule tells us a lot about the world. Rational choice theory also uses this rule. It is as if rational choice theory sees through a glass darkly: the use of the rule is why it appears to give insights into behaviour. But these insights are often distorted by the insistence on rationality.

800 Massey: Just very quickly going back to Ormerod, I am thinking about the modelling and particularly the modelling with zero cognition. In the 1960s I worked for a while in the mathematical modelling of cities, and there was this thing called 'social physics'. I just wondered if you could reflect a bit on what that kind of modelling means for the other ways in which we think about the social or the social interaction. 
Ormerod: Economics is essentially a theory about individual behaviour, about the cognitive ability of agents to gather and process information, and the rules which they use to do so. The new type of modelling, social physics as you say, is really based on the ideas that, first, agents have limited abilities to understand their environment, and, second, that agents are embedded in networks of other agents. So in a complicated environment, a very useful decision rule might be simply to look at what other agents are doing, and if enough of them are taking a particular action, you do the same. There is a lot of very exciting and powerful work-powerful in the scientific sense that it explains empirical phenomena wellbeing done using these principles. In these models, agents have pretty low cognition about their environment, so they use rules of thumb. Almost all of this work is being done outside economics. For example, there is now a discipline called 'econophysics', which is getting recognition. The lead editorial of Nature recently called for more support for it. Some highly numerate sociologists such 815 as Duncan Watts at Columbia are working in this area, as are computer scientists. It is going on all around economics and, although in policy terms economics is actually very important, in intellectual terms it is shrinking, and a lot more is being done outside that and people are not necessarily labelling themselves. They are interested in explaining empirical phenomenon and using a variety of

820 approaches and it is starting to impinge within economics, but quite slowly.

Thrift: One of the debates that the Academy could have concerns rationality and cognition and the reason for that is because this has become an immensely practical project. People in all sorts of ways are trying to build these kinds of debates, whether it is in robotics or computing. I think that on the whole social sciences have taken less notice of that than they should have, because I think there are some genuinely interesting things going on. I researched the ethnography of traders, and I came to the conclusion that although it looks as though these people are agents, they are actually doing very little at all, most of the time. They are actually sweeping up after the markets have already gone in certain ways so there are some interesting 830 things around that. But the whole thing around cognition and rationality strikes me as important because I think it is at this point in time practically being redefined in a series of fields. A second topic for debate that seems important is around animal rights, this is an example of an area where there is a genuine debate within society about actors and rationality. Then the third topic comes back to something that people were saying and it is about the nature of modern data. I am very interested in the way that social facts start to be redefined once you actually start to have continuous datasets. The fact that actually at that point it may be possible that they become much more mutable than they had been before, seems to me very relevant in terms of the ESRC and a series of other institutions, because in certain ways 840 they are trying to move towards, if you like, continuous datasets which would read off individuals in certain kinds of ways.

Question: Could the Academy be a non-disciplinary context which takes the notion of social science as a central tenet and therefore provides a meeting place for people to talk about these sorts of things? 
Massey: I am very preoccupied with somehow translating notions of the academy into public policy and therefore constantly confronting debates around evidence based policy and being very aware of debates about knowledge which do not quite fit easily with those sorts of assumptions. So, one of my answers to the question is I found it quite reinforcing and helpful to think that there is perhaps a bit more substance than some of the gut instinct that many of us have and that we ought to be engaged in these sorts of things. Taking it forward is a bit more difficult, and part of what I heard also some discussion within the Academy around the nature of disciplinarity, which partly seems to be at the core of a lot of discussions about what is the social, whether or not the social can only dealt with by the imperialistic claims of the sociologist, or whether the social could be taken on board by breaking down some of the boundaries between space and time and various other dimensions of psychology, especially in going back to the early genealogy of some of the disciplines where these things were less closely guarded frontiers.

855 Question: What I think is interesting is how the social sciences as a whole have a particular way of thinking about the world and I wanted to related that to some important remarks that Ormerod made about the way in which the relationship between sociophysics and econophysics and modelling. I take from the kind of remarks that were being made that there was some anxiety about as to whether the social sciences are being invaded by these physicists. Well, actually I think that the exact opposite is the case and I think Ormerod put it extremely nicely to show that what is important in his example of a market trading are institutions, the way in which the institution of the continuous double auctions evolve, and networks. What physicists ought to be doing, and indeed in my experience, to some extent are doing. The same is true of computer scientists coming to social sciences and saying 'you know about the social and we want to use your knowledge about the social or your understanding of sociology in order to design better information technology or to understand better how complex systems of particles work'. So perhaps it could be seen to be the exact reverse of the kind of feeling that the panel is putting forward, that we're kind of subservient or under threat from these physicists, we actually know what we are doing and they do not. One of the problems is that the physicists that you are talking about do not know what we do, that is one of the problems. In one of the areas Ormerod mentioned Duncan Watts, who was a physicist who came into sociology, yet there is a lot of the work that has been done in network analysis. These physicists completely ignored what social scientists have done in that area and assume that we do not know anything about that. I think you are right that there ought to be much more two way co-operation rather than imperialistic physics or imperialist sociology.

Question: Just to expand a point that was made and which I think was about practice. What we ought to reflect on is what the Academy does and looking at models of practice, other communities of practice and how we might be able to learn from what we are actually investigating to think about how we operate ourselves, what it is to do social science and what it is to be a social scientist. So I think there is a whole scope there, of how we connect to what we are investigating that might enable us to judge what is good social science. So I think there is a whole discussion there about 
reflecting on the objects of social science and thinking about what the implications for effective practice.

Urry: Could each panellist respond to one point that has been made, and in particular Ormerod: have you learned anything about the social that you can take back to economics?

Ormerod: Well, I have learned a lot of new names! I think people here today are talking, in their various ways, about complex systems. There are properties of the system as a whole that cannot readily be deduced from a description of its component parts. In part, this is due precisely to the fact that agents operate within society, within networks, and imitative behaviour within such networks is a very important feature of the real world. In part, it is due to institutions, and the crucial role that these play in outcomes.

The conferences I go to are multidisciplinary but they do not have enough social scientists in them and hardly any economists-they are computer scientists, physi895 cists, mathematicians, one or two sociologists. So there is a lot of scope for bringing social knowledge to these people. Often, non-social scientists are pretty naïve about economics or society. As a result they sometimes make some very silly mistakes in a model and do things that are just wrong. But they also bring good techniques and open minds.

900 I think we should be reaching out to these kinds of people. I do try to take social concepts into economics, but it is a hard struggle. A more effective strategy is to build a very broad coalition much bigger than economics, so it will simply become surrounded.

Urry: One of the things that Scott did was to develop a processual model of sociology, which is different from any of the other speakers and I thought that was interesting since such a discipline was seen to have certain emergent properties and whether, if that was the case, was that how you were seeing what you were describing?

Scott: Yes, I think so. Since you asked us to comment on one point, that is the area that I wanted to comment on, particularly in relation our knowledge of the history of our discipline. The important thing is to get away from the idea that we should read only the things produced in the last 10 years or that we need 'new departures', and so on. It is important to understand the history of the social sciences, and I think the example of Tarde is important in that. I would say we do need to have a better understanding of the history of our discipline, but if the crucial period of the 1890s to the 1930s was a 915 period in which disciplinary boundaries were more fluid than they have been recently and disciplines were in the process of formation, the important question is that of who's history we should know about. We should not confine our knowledge of history to the particular discipline that we happen to be working in at the moment. If we go beyond it, then we are necessarily engaging with that broader view of the social and how it is changing over time.

Massey: Two quick points, one just provoked a sense of alarm when someone talked about me saying we should determine the future. There is no way we can do that, obviously, but we do a bit more than simply represent it and the very ways we understand it has some effect upon it and that is all I was meaning. I would just like to go 


\section{4 f. Urry et al.}

back as I was interested that the two geographers on the panel ended up with exactly the same question. It is one we cannot pursue further now, but I would love to sometime and that is 'Who is the we?'. I think there is one way in which it is figured in our debate, the trans-human, the non-human. The things that both Thrift and I referred to have come up as partly contextual, partly in a slightly instrumental way, they are things through which we construct the social in all kinds of ways, but there is also the other question of them being part of how are we going to live together and that is where I think it is about nature. It does raise the question of our living somehow responsibly in a non-human environment. So there are those two particular ways in which I would like to, at some point, think through how the 'we' is going to be expanded and on what terms because I think it is the terms of the expansion that are in question.

Thrift: Some of my best friends really are physicists, and recently I had to lead a discussion on what makes good science. The interesting thing was everyone agreed that what it was really about was the ability to take risks. Risks which involve designing experiments which allow the materials to speak back to you, to say something new in some way or another. It seems to me that, actually in a sense, social science itself is indeed in that kind of risky phase at this point in time. There are a whole series of projects which are experiments which are trying to allow the materials to speak back and some of them are going to fail but some of them, I think, will succeed, and I think that social science will be much stronger for this period of experimentation, I have to say.

Urry: Thanks very much. It seems to me that there are a number of potential future events that might get organised by the Academy and some of those that have been mentioned would include, first, rationality and cognition. Second, there is a debate to be had around the changing nature of contemporary data and of its continuous form. Third, there is something to debate around rights, of animals, but also of the environment; it is interesting that all new constitutions now being formed generally have rights of the 'environment' featured strongly within them. Fourth, there is something around the significance of networks. Networks have been a kind of understated 'presence' in a many contributions people have made here. Of course there are very many different forms and characteristics of those networks, sometime they are 'social', sometimes they are 'social plus an array of other entities'. A final topic would be the one that Doreen has just referred to which is who is the 'we' and how should it be expanded and represented intellectually and especially politically?

\section{Notes}

960 1. This is a very foreshortened argument, and it is not possible here to draw out the detail of the argument or its socio/political implications. For this, and for elaboration of other parts of this paper, see Massey (2005).

2. It is worth noting that this definition of space as the dimension of multiplicity is distinct from that other commonly-used definition of it as the dimension of extension. The move from extension to multiplicity is crucial in a host of ways, philosophical and political. 


\section{References}

Alexander, J. (2006) The Meanings of Social Life. A Cultural Sociology (Oxford: Oxford University Press).

Arthur, W. B. (1989) Competing technologies, increasing returns, and lock-in by historical events, Economic fournal, 99, pp. 116-131.

de Gulimi, C., Gallegati, M. \& Ormerod, P. (2004) Scaling invariant distributions of firms' exit in OECD countries, Physica A, March.

Fabian, J. (1983) Time and the Other: How Anthropology Makes its Object (New York: Columbia University Press).

Farmer, J. D., Patelli, P. \& Zovko, I. I. (2003) The predictive power of zero intelligence in financial markets. Condensed Matter archive 0309233 (Los Alamos: National Laboratory).

Grossberg, L. (1996) The space of culture, the power of space, in: I. Chambers \& L. Curti(Eds) The Post-colonial Question, pp.169-188 (London: Routledge).

Kahneman, D. (2003) Maps of bounded rationality: psychology for behavioral economics, American Economic Review, 93, pp. 1449-1475.

Kirman, A. (1995) The behaviour of the foreign exchange market, Bank of England Quarterly Bulletin, August.

Latour, B. (1993) We Have Never Been Modern (Cambridge, MA: Harvard University Press).

Latour, B. (1999) Ein Ding ist ein Thing-a (philosophical) platform for a left (European) party, Soundings: A fournal of Politics and Culture, 12, Summer, pp.12-25.

Lazzarato, M. (2005) Introduction, in: G. Tarde Underground. Fragments of Future Histories (Brussels: Les Maîtres de Formes Contemporains).

980 Lovelock, J. (2006) The Revenge of Gaia (London: Allen Lane).

Massey, D. (2004) Geographies of responsibility, Geografiska Annaler, Ser. B., 86(1), pp. 5-18.

Massey, D. (2005) For Space (London: Sage).

Netz, R. (2004) Barbed Wire. An Ecology of Modernity (CT: Wesleyan University Press).

Ormerod, P. \& Rosewell, B. (2003) What can firms know. Plenary talk, Proceedings of the North American Association for Computational and Social Science, Pittsburgh.

985 Scott, J. (2005a) Sociology and its others: reflections on disciplinary specialisation and fragmentation, Sociological Research Online, 10(1). Available at http://www.socresonline.org.uk/10/1/ scott.html

Scott, J. (2005b) Fallacies in the critique of disciplinary sociology, Sociological Research Online, 10(3). Available at http://www.socresonline.org.uk/10/3/scott.html

Thrift, N. J. (2005a) Knowing Capitalism (London: Sage).

990 Thrift, N. J. (2005b) From born to made: technology, biology and space, Transactions of the Institute of British Geographers, NS30, pp. 463-476.

Thrift, N. J. (2006) Re-inventing invention: new forms of capitalist commodification, Economy and Society, 35, pp. 279-306.

Virno, P. (2005) A Grammar of the Multitude (New York: Semiotext(e)).

995 Virno, P. (2006) Reading Gilbert Simondon. Transindividuality, technical activity and reification, Radical Philosophy, 136, pp. 34-43.

Sloterdijk, P. (2005a) Foreword to the theory of spheres, in: M. Obanian \& J. C. Royaux (Eds) Cosmograms, pp. 223-240 (New York: Lukas and Sternberg).

Sloterdijk, P. (2005b) Atmospheric politics, in: B. Latour \& P. Weibel (Eds) Making Things Public. Atmospheres of Democracy, pp. 944-951 (Cambridge, MA: MIT Press).

Wilkinson, I. (2005) The Sociology of Suffering (Cambridge: Polity Press).

1000 Wolf, E. (1982) Europe and the People Without History (London: University of California Press). 